DOI: 10.1002/adfm.201102941

Submitted to

\title{
Silaindacenodithiophene based low band gap polymers - the effect of fluorine substitution on device performances and film morphologies.
}

By Bob C. Schroeder, Zhenggang Huang, Raja Shahid Ashraf,* Jeremy Smith, Pasquale D' Angelo, Scott E. Watkins, Thomas D. Anthopoulos, James R. Durrant and Iain McCulloch

B. C. Schroeder, Z. Huang, Dr. R. S. Ashraf, Prof. J. R. Durrant, Prof. I. McCulloch

Department of Chemistry and Centre for Plastic Electronics

Imperial College London

London, SW7 2AZ (United Kingdom)

E-mail: r.ashraf@imperial.ac.uk

Dr. J. Smith, Dr. P. D’Angelo, Dr. T. D. Anthopoulos

Department of Physics and Centre for Plastic Electronics

Imperial College London

London, SW7 2AZ (United Kingdom)

Dr. S. E. Watkins

CSIRO Materials Science and Engineering

Melbourne, VIC 3169 (Australia)

Keywords: silaindacenodithiophene, hole mobility, solar cell, fluorine, conjugated polymers

Abstract: Silaindacenodithiophene is co-polymerized with benzo[c][1,2,5]thiadiazole (BT) and 4,7-di(thiophen-2-yl)benzo[c][1,2,5]thiadiazole (DTBT), respectively their fluorinated counter parts 5,6-difluorobenzo[c][1,2,5]thiadiazole (2FBT) and 5,6-difluoro-4,7-di(thiophen2-yl) benzo[c][1,2,5]thiadiazole (2FDTBT). The influence of the thienyl spacers and fluorine atoms on molecular packing and active layer morphology is investigated with regard to device performances. BHJ solar cells based on silaindacenodithiophene donor-acceptor polymers achieved PCE's of $4.5 \%$ and hole mobilities of as high as $0.28 \mathrm{~cm}^{2} /(\mathrm{Vs})$ were achieved in OFET.

\section{Introduction}

Over the last decade organic semi-conducting polymers have received a lot of attention, with their performances in organic field effect transistors (OFET) and organic photovoltaic devices 
Submitted to

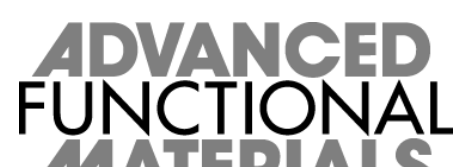

1 (OPV) increasing significantly. ${ }^{[1]}$ The improved performance is not only the result of a better

2 understanding of the physics governing the various charge generating and transport processes

3 and the improved processing techniques, but also due to the development of new donor-

4 acceptor semiconducting materials. ${ }^{[2]}$

5 Silole based building blocks, such as dithienosilole and indacenodithiophene (IDT), have 6 proven their potential in OPVs, as well as in OFETs, when introduced into donor-acceptor 7 polymers. $^{[3]}$ Extended $\pi$-conjugated ladder type monomers like indacenodithiophene are attractive for incorporation into donor-acceptor polymers partly because the backbone rigidification leads to an improved conjugation length (enhanced coplanarity of repeat units), resulting in higher short-circuit currents $\left(J_{\mathrm{SC}}\right)$ due to an improved long wavelength photon absorption. Besides the improved optical properties, the silicon bridge stiffens the polymer backbone and reduces conformational disorder. This reduction in energetic disorder has been reported to increase the charge carrier mobility. ${ }^{[4]}$ Recently the introduction of silicon atoms into the indacenodithiophene backbone was observed to provide high photocurrent efficiencies and high charge carrier mobilities. ${ }^{[5]}$ In addition, the separation between the antibonding lobes located on the carbon atoms of linked aryl rings in the indacenodithiophene unit increases, and this reduction in antibonding energy manifests as a reduction in the HOMO energy level, thus leading to an increase in the open-circuit voltage $\left(V_{\mathrm{OC}}\right)$ of solar cells. It is also possible in some cases to have effective orbital mixing between the silicon's $\sigma^{*}$-orbital and the $\pi^{*}$-orbital of the adjacent butadiene fragment, stabilizing the LUMO, with correspondingly lower bandgaps than their carbon bridged counterparts. ${ }^{[6]}$

Recently, several groups have reported fluorine substituted conjugated polymers with highefficiency solar cells. ${ }^{[7]}$ Fluorine is smaller in size than other electron withdrawing groups 24 (e.g. cyano or trifluoromethyl groups) and can be introduced within the polymer backbone 25 without causing too much steric hindrance. 
Submitted to

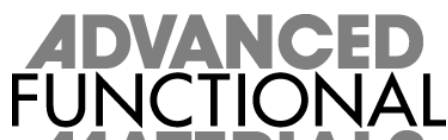

(SiIDT) with benzo[c][1,2,5]thiadiazole

2 (BT), 4,7-di(thiophen-2-yl)benzo[c][1,2,5]thiadiazole (DTBT) respectively, has led to high

$3 V_{\mathrm{OC}}$ values in OPV devices. ${ }^{[5]} \mathrm{We}$ expect to further increase the OPV performances of SiIDT

4 based polymers by increasing the $V_{\mathrm{OC}}$ of the aforementioned polymers due to the introduction

5 of electron-withdrawing fluorine atoms on the polymer backbone, thus lowering the

6 polymer's HOMO energy level and potentially increasing the PCE. ${ }^{[7 a, 8]}$ Herein we report the

7 co-polymerization of 5,6-difluorobenzo[c][1,2,5]thiadiazole (2FBT) and 5,6-difluoro-4,7-

8 di(thiophen-2-yl) benzo[c][1,2,5]thiadiazole (2FDTBT) with the SiIDT donor moiety. The

9 influence of the thienyl spacers and the fluorine atoms on molecular packing and active layer morphology will be evaluated with regard to device performance.

\section{Results and Discussion}

\subsection{Synthesis}

The silaindacenodithiophene (SiIDT) monomer was obtained according to our previously published synthetic pathway. ${ }^{[5 b]}$ All four copolymers shown in Scheme 1 were synthesized by Stille cross-coupling reactions under microwave heating conditions, yet two different catalytic systems and solvents respectively, were used depending on the aryl groups to couple. In the case where the stannylated SiIDT monomer was coupled to a phenyl ring, tetrakis(triphenylphosphine) palladium was used as catalyst and $o$-xylene as solvent. However, when the SiIDT unit was coupled to a thienyl group, tris(dibenzylideneacetone) dipalladium, together with tri(o-tolyl) phosphine was used as catalytic system in chlorobenzene.

It is essential for the performance of OFETs and OPVs to employ high quality semiconducting materials, i.e. the polymer should have no structural defects and contain neither organic, nor inorganic impurities. By using metal catalyzed coupling reactions, the probability of structural defects in the polymer chain can be minimized, but there is typically no 
Submitted to

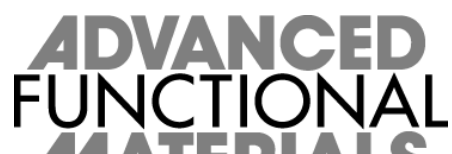

14 A

1 deliberate control over the chemical nature of the chain ends, unless an endcapping step at the

2 end of the polymerization is used. Even though the concentration of end-groups is very low in

3 a polymer chain of typical molecular weight, their effects on charge trapping, hysteresis and

4 film morphology can be significant. ${ }^{[9]}$ In order to avoid these undesirable effects, all the

5

6 synthesized polymers were end-capped with chemically inert phenyl groups. Organic and inorganic impurities were removed by precipitating the polymer in methanol, followed by Soxhlet extractions with polar and non-polar solvents. After the Soxhlet extractions, the polymer was dissolved in chloroform and washed with an aqueous sodium diethyldithiocarbamate solution to remove residual palladium impurities.

All polymers were synthesized with high molecular weights and comparable polymerization degrees, with the SiIDT-BT polymer having the highest molecular weight $\left(M_{n}=30.0 \mathrm{~kg} / \mathrm{mol}\right)$. The molecular weights of all polymers are summarized in Table 1. The polymers are readily soluble in common organic solvents, except for the fluorinated polymers, which will only dissolve when heated in chlorinated solvents. Thermal gravimetric analysis (TGA) confirmed the stability of all the polymers and a 5\% weight loss could not be observed at temperatures lower than $400^{\circ} \mathrm{C}$ (see Figure S18 in the Supporting Information). Differential scanning calorimetry (DSC) shows a broad melt around $310^{\circ} \mathrm{C}$ with a sharper crystallisation on cooling at around $290^{\circ} \mathrm{C}$ for SiIDT-BT, but for all the other polymers no obvious thermal transitions were identified in the temperature range of 0 to $350^{\circ} \mathrm{C}$ (see Figure $\mathrm{S} 19$ to $\mathrm{S} 23$ in the Supporting Information).

\subsection{Optical Properties}

The UV-vis. absorption spectra of the polymers in dilute chlorobenzene solution and thinfilms spin-coated on glass substrates are shown in Figure 1. The detailed absorption data, 
Submitted to

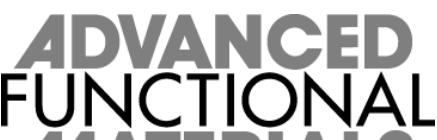

MATERIALS

1 including absorption maxima in solution and film, as well as the corresponding absorption

2 onsets and bandgaps are presented in Table 2.

3 Even though the polymer backbones of SiIDT-BT and SiIDT-2FBT are very similar and the

4 fluorine atoms are small in size, they have a large influence on the molecular packing. In

5 solution, the absorption feature of SiIDT-2FBT is blue-shifted by $40 \mathrm{~nm}$ compared to SiIDT-

6 BT. The blue-shift is partially attributed to its lower molecular weight and the presence of

7 fluorine on the benzothiadiazole (BT) unit. The atomic radius of fluorine $(0.50 \AA)$ is larger than that of hydrogen $(0.25 \AA)$ and expected to give rise to steric hindrance between the fluorine atoms on the BT unit and the adjacent thiophene of the SiIDT moiety. ${ }^{[10]} \mathrm{We}$ attribute the blue shift of the absorption spectrum to the reduced conjugation length of SiIDT2FBT. In the solid state however, the backbone twist is suppressed due to planarising intramolecular interactions between the fluorine atoms on the BT core and the sulfur atom on the neighboring SiIDT unit, resulting in similar absorption peaks for SiIDT-BT and SiIDT2FBT with a more pronounced vibronic structure compared to the solution absorption spectra. ${ }^{[1]}$ In the case of SiIDT-DTBT and SiIDT-2FDTBT the influence of the fluorine atoms on the backbone twist is diminished because the additional thiophene ring between the SiIDT moiety and the BT core acts as a spacer, thus minimizing the sterical hindrance between the two bulkier aromatic units.

Both polymers, SiIDT-BT and SiIDT-2FBT, exhibit two well defined absorption peaks, one at higher energies resulting from $\pi-\pi^{*}$ transitions and a more important one at lower energies caused by the internal charge transfer (ICT) from the donor to the acceptor part of the polymer backbone. A different behavior can be observed, when thienyl spacers are introduced between the donor and acceptor parts of the polymer backbone, as it is the case for SiIDTDTBT and SiIDT-2FDTBT. The UV-vis. spectra still present two different absorption 
Submitted to

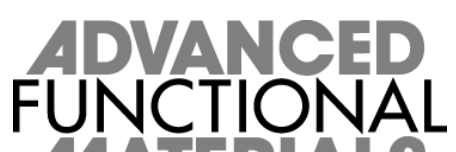

MATERIALS

1 transition peaks are more intense and observed at longer wavelengths, compared to the

2 absorption peaks of SiIDT-BT and SiIDT-2FBT, resembling rather low-wavelength

3 shoulders than independent peaks.

4 The ionization potentials of all polymers were measured by ultraviolet photoelectron spectroscopy in air (UV-PESA) and cyclic voltammetry (CV); the results are summarized in Table 2. The measured energy levels follow the same trends within both techniques, but there are significant differences when comparing the data from both techniques. These differences emphasize that it is very difficult to measure the frontier-orbital energy levels accurately because the values obtained depend not only on the experimental technique, but can also be influenced by the morphology, hence, and the measured energy levels should be regarded as estimated values. PESA, as well as CV measurements, confirm that the introduction of electron withdrawing fluorine atoms lower both HOMO and LUMO energy levels to a similar degree, and thus have a negligible effect on the bandgap of SiIDT-2FBT and SiIDT2FDTBT compared to their non-fluorinated counter-parts.

Quantum mechanical calculations were performed to predict the energy levels and model the molecular orbital distributions. Density functional theory calculation, using B3LYP/6-31G* model, were performed on trimers with methyl substituted alkyl chains for simplicity. In our study, the theoretical values were all higher in energy than the experimental values, which we attribute to limitations within the DFT model to describe low-band gap semi-conducting polymers. ${ }^{[12]}$ Nevertheless, the calculated values are consistent with the trends observed in the experimental PESA and CV data. The calculations predict lower lying HOMO energy levels for the fluorinated polymers, as well as increase in the HOMO when thienyl spacers are introduced between the donor and acceptor parts of the polymer backbone. The theoretical calculations predict furthermore a delocalization of the HOMO over the entire polymer backbone and a preferential localization of the LUMO on the BT moiety for all four BT 
Submitted to

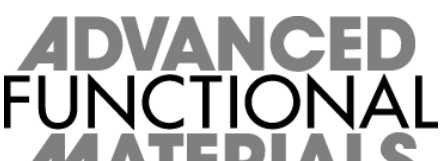

1 containing polymers. The molecular orbitals of SiIDT-2FBT and SiIDT-2FDTBT are

2 depicted in Figure 2; the energy distributions for SiIDT-BT and SiIDT-DTBT can be found

3 in the supporting information.

4

\subsection{Field-Effect Transistor Devices}

Field effect transistors with top-gate, bottom-contact device architecture were fabricated to investigate the charge carrier mobility of SiIDT based polymers. After thermal annealing at $180^{\circ} \mathrm{C}$, the hole mobilities were extracted from the transfer characteristics in saturation and are summarized in Table 3. The fluorine-sulfur interactions were expected to favor polymer backbone planarization, potentially therefore reducing intermolecular packing distances and thus having a positive effect on hole mobility. However the opposite effect is observed experimentally, both fluorinated polymers (SiIDT-2FBT and SiIDT-2FDTBT) exhibit lower hole mobilities, $0.004 \mathrm{~cm}^{2} / \mathrm{Vs}$ and $0.19 \mathrm{~cm}^{2} / \mathrm{Vs}$, than their non-fluorinated counterparts. It is speculated that the lower electron density on the polymer backbone, induced by the presence of fluorine atoms, hinders hole mobility, or hole injection, which compensates the beneficial effect of backbone planarity. The introduction of thienyl spacers into the polymer backbone however, has a positive effect on the hole mobility $\left(0.28 \mathrm{~cm}^{2} / \mathrm{Vs}\right.$ and $\left.0.19 \mathrm{~cm}^{2} / \mathrm{Vs}\right)$. SiIDTDTBT and SiIDT-2FDTBT exhibit several orders of magnitude higher hole mobilities, than the polymers with no spacers in the backbone. The transfer curves and output characteristics of the OFET devices can be found in the Supporting Information. To understand this significant difference in mobility, drop cast polymer films were annealed for 10 minutes at $180^{\circ} \mathrm{C}$ and probed by X-ray diffraction (XRD). The complete XRD spectra of all four SiIDT polymers before and after annealing can be found in the Supporting Information. As can be seen in the diffraction patterns presented in Figure 3, SiIDT-BT and SiIDT-2FBT both show

25 intense diffraction peaks at $5.3^{\circ}$ and $10.6^{\circ}$, thus giving evidence for a crystalline 
Submitted to

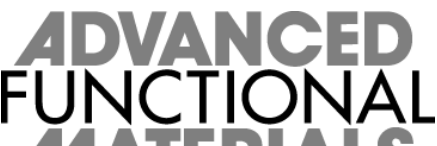

MATERIALS

1 microstructure with a lamellar packing distance of $16.6 \AA$. Interestingly, the SiIDT-BT has a

2 very amorphous microstructure before annealing, and only becomes highly ordered upon

3 annealing at $180^{\circ} \mathrm{C}$ for 10 minutes.

4 We further investigated OFET devices based on SiIDT-BT before and after annealing, but the

5 hole mobility remained virtually unchanged $\left(0.012 \mathrm{~cm}^{2} / \mathrm{Vs}\right.$ before and $0.014 \mathrm{~cm}^{2} / \mathrm{Vs}$ after annealing). However a considerable shift in threshold voltage from $-7 \mathrm{~V}$ before to $-27 \mathrm{~V}$ after annealing was observed. The polymer film morphology was investigated by AFM before and after annealing (See Figure S26 in the Supporting Information) and a surface roughening was noticed. We attribute the threshold voltage increase in part to the possible introduction of new trap states at the dielectric interface formed during the crystallization of the polymer at high annealing temperatures, and corresponding surface roughening.

On the other hand, SiIDT-DTBT and SiIDT-2FDTBT were found to be less crystalline than the aforementioned polymers, showing broader and less intense diffraction peaks at $5.1^{\circ}$, respectively $5.3^{\circ}$. The diffraction peak of SiIDT-DTBT is sharper $(\mathrm{FWHM}=0.46)$ than the one for SiIDT-2FDTBT (FWHM = 1.23), thus indicating a higher degree of crystallinity. In addition, a change in the position of the diffraction peak of SiIDT-DTBT $\left(5.1^{\circ}\right)$ compared to SiIDT-2FDTBT $\left(5.3^{\circ}\right)$ is observed, which translates into a larger lamellar stacking distance of $17.4 \AA$. It is worth mentioning, that in this study the least crystalline polymers, SiIDTDTBT and SiIDT-2FDTBT, gave the highest mobilities. In previously published reports it has also been found that polymers that do not exhibit a high degree of long range order can lead to high hole mobilities, believed to be due to excellent one dimensional transport along the polymer backbone with short favourable hops between chains facilitating charge percolation. ${ }^{[13]}$

\subsection{Photovoltaic Properties}


Submitted to

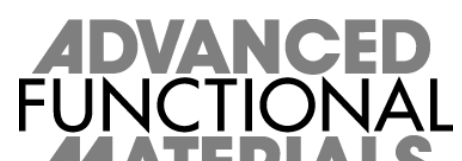

1 To evaluate the photovoltaic performances of the SiIDT polymers, bulk hetero-junction

2 (BHJ) solar cells with conventional device structure consisting of

3 ITO/PEDOT:PSS/Polymer:PC $71 \mathrm{BM} / \mathrm{Ca} / \mathrm{Al}$ were prepared and tested under simulated $100 \mathrm{~mW}$

$4 \mathrm{~cm}^{-2}$ AM1.5G illumination. The J-V curves and external quantum efficiencies (EQE) of the

5 organic photovoltaic cells (OPV) are presented in Figure 4. The corresponding open-circuit

6 voltages $\left(V_{\mathrm{OC}}\right)$, short-circuit currents $\left(J_{\mathrm{SC}}\right)$, fill factors $(\mathrm{FF})$ and power conversion efficiencies

7 (PCE) are summarized in Table 4.

8 Figure 4 shows the external quantum efficiency (EQE) of the best devices of each blend ratio

9 as a function of wavelength, which is consistent with the polymer/fullerene blends UV-vis.

10 absorption spectra. Convolution of these EQE spectra with the AM1.5 spectra gave calculated

11 short circuit current densities in good agreement $\left.( \pm 0.5 \mathrm{~mA} \mathrm{~cm})^{-2}\right)$ with those measured under

AM1.5 simulated sunlight (Table 4). The EQE spectrum of SiIDT-DTBT and SiIDT-

2FDTBT extends further to the red than SiIDT-BT, consistent with the insertion of thienyl spacer leading to extended red absorption in these polymers. The EQE of both of these polymers extends up to $700 \mathrm{~nm}$, while that of SiIDT-BT ranges only to $650 \mathrm{~nm}$. We attribute the higher EQE response in the visible region to the corresponding strong absorbance of the blends, resulting from both the intrinsic absorption of the polymers and the presence of a high content of $\mathrm{PC}_{71} \mathrm{BM}$, which absorbs significantly at $400-500 \mathrm{~nm}$. The broad coverage of the solar spectrum of the solar cell results in a desirable $J_{\mathrm{SC}}$ under illumination with white light. The device of SiIDT-BT blend exhibited a higher EQE response relative to other polymer blends with a maximum of $60 \%$ at about $518 \mathrm{~nm}$, consistent to its higher photocurrent.

Devices based on SiIDT-BT and SiIDT-DTBT have been reported previously, with device efficiencies of up to $4.5 \% .^{[5]}$ We expect to further increase the device performance by introducing fluorine atoms on the polymer backbone. However, the PCE of the device based on SiIDT-2FBT is heavily limited by its low $J_{\mathrm{SC}}$, despite the fact that the UV-vis. absorption 
Submitted to

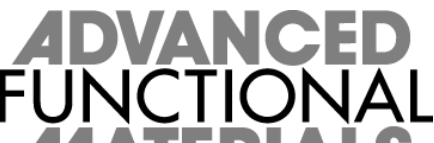

14 A spectrum of SiIDT-2FBT is slightly more red-shifted than the SiIDT-BT one. The EQE spectra indicate that this loss of photocurrent results from a loss of photocurrent density from both polymer and $\mathrm{PC}_{71} \mathrm{BM}$ absorption. Photoluminescence (PL) quenching data indicated similar high polymer PL quenching for both polymers, indicating that this loss of photocurrent cannot be assigned to exciton diffusion limitations (see Figure 5). To evaluate further the lower $J_{\mathrm{SC}}$ for the SiIDT-2FBT $/ \mathrm{PC}_{71} \mathrm{BM}$ device, the blend morphologies were investigated by close contact atomic force microscopy (AFM), as shown in Figure 6. While the topography image of SiIDT-BT/PC $71 \mathrm{BM}$ shows a relative homogeneous film microstructure, large phase segregation $(50-200 \mathrm{~nm})$ is found in the topography image of SiIDT-2FBT/PC ${ }_{71}$ BM. Transmission electron microscopy (TEM) confirmed this difference in film microstructure, with excellent agreement between the AFM and TEM data (see Figure 6). The TEM data employed an iodine stain, with the more prevelant darker island evident in the TEM image corresponding to $\mathrm{PC}_{71} \mathrm{BM}$ rich domains. A similar phenomenon was observed by $\mathrm{Yu}$ and co-workers, who found that introducing fluorine to the polymer backbone changes initially homogenous blend morphology to a heterogeneous one with large phase segregation and non-bicontinuous features. ${ }^{[14]}$ The extent to which the coarse film microstructure is the direct cause of the lower photocurrent for SiIDT-2FBT/PC ${ }_{71} \mathrm{BM}$ is not obvious. The PL quenching data indicates that the lower photocurrent is most probably not associated with exciton diffusion limitations, suggesting that the domains observed in the AFM and TEM images do not correspond to pure polymer and pure fullerene domains. Rather it appears more likely that this coarser domain structure reduces the efficiency of charge collection in the SiIDT-2FBT/PC 71 BM devices.

Although the HOMO energy levels for SiIDT-BT and SiIDT-2FBT measured by PESA and $\mathrm{CV}$ are very similar, a slightly larger $V_{\mathrm{OC}}$ is observed in the devices based on SiIDT-2FBT as expected from the DFT calculations. Devices based on SiIDT-DTBT display lower $V_{\mathrm{OC}}$ than 
Submitted to
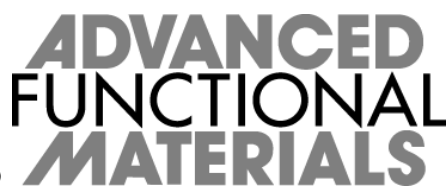

1 SiIDT-BT based devices due to the addition of the thienyl spacer, which primarily increases

2 the $\pi$ electron density, thus raising the HOMO energy level. The introduction of thienyl

3 spacers into the polymer backbone also results in a finer blend microstructure (see Figure 6).

4 SiIDT-DTBT based devices have similar $J_{S C}$ and $F F$ values as the SiIDT-BT polymer but the

5 overall device performance is lower because of the smaller $V_{\mathrm{OC}}$

6 When devices employ SiIDT-2FDTBT, the addition of the thienyl spacers leads again to a

7 smaller $V_{O C}$ compared with SiIDT-2FBT based devices. However, there are significant

8 improvements in both $J_{S C}$ and $F F$ which increase the device efficiency to $4.3 \%$. The increase

9 in photocurrent may be attributed to the red-shifted polymer absorption spectrum.

Additionally, thienyl spacer introduction offers a much more homogeneous microstructure to

SiIDT-2FDTBT/PC ${ }_{71} \mathrm{BM}$ compared with SiIDT-2FBT/PC ${ }_{71} \mathrm{BM}$ (see Figure 6).

\section{Conclusion}

In conclusion, we have synthesized a series of low-band gap polymers incorporating the

SiIDT donor moiety and we investigated the effect of polymer fluorination on device performance and morphology. The incorporation of fluorine atoms to the polymer backbone was shown to influence both the polymer electronic energy levels and thin film morphology. The highest OPV device PCE achieved was $4.3 \%$ for the SiIDT-2FDTBT polymer, compared to $3.6 \%$ for its non-fluorinated counterpart. In field effect transistor devices, the SiIDT based polymers achieved high hole mobilities, up to $0.28 \mathrm{~cm}^{2} / \mathrm{Vs}$, with the unexpected

21 trend being that the less crystalline thin films exhibited the higher mobilities.

\section{Experimental Section}

Characterization: Photo Electron Spectroscopy in Air (PESA) measurements were recorded 
Submitted to 1 A E R

FUNCTIONAL

1 number of 0.5 . Number-average $\left(\mathrm{M}_{\mathrm{n}}\right)$ and weight-average $\left(\mathrm{M}_{\mathrm{w}}\right)$ molecular weights were

2 determined with an Agilent Technologies 1200 series GPC in chlorobenzene at $80{ }^{\circ} \mathrm{C}$, using

3 two PL mixed B columns in series, and calibrated against narrow polydispersity polystyrene

4 standards. Electron Ionization mass spectrometry were performed with a Micromass

5 AutoSpec Premier mass spectrometer. UV-Vis absorption spectra were recorded on a UV-

61601 Shimadzu UV-Vis spectrometer. AFM was performed on a 5500 AFM from Agilent

7 Technology in tapping mode and TEM images were recorded on a high-resolution JEOL 2010

8 TEM (80-200 kV) with interchangeable pole-pieces. DSC experiments were carried out with a

9 Metler Toledo DSC822 instrument. TGA plots were obtained with a Perkin Elmer Pyris 1

10 TGA. Cyclic voltammograms (CV) were obtained using a cylindrical platinum working

11 electrode and a platinum mesh counter electrode in acetonitrile at a potential scan rate of 10

$12 \mathrm{mV} \cdot \mathrm{s}^{-1} \cdot \mathrm{Ag} / \mathrm{Ag}^{+}$was used as reference electrode and calibrated against ferrocene. All the

13 measurements were carried out in an argon-saturated solution of $0.1 \mathrm{M}$ of

14 tetrabutylammonium hexafluorophosphate $\left(n-\mathrm{Bu}_{4} \mathrm{NPF}_{6}\right)$ in anhydrous acetonitrile. X-ray

15 diffraction (XRD) measurements were carried out with a PANALYTICAL X'PERT-PRO

16 MRD diffractometer equipped with a nickel-filtered $\mathrm{Cu} K \alpha_{1}$ beam and a X' CELERATOR

17 detector, using a current of $40 \mathrm{~mA}$ and an accelerating voltage of $40 \mathrm{kV}$.

Polymer Synthesis: Condition A. A microwave vial was charged with bis(trimethylstannyl) monomer $1(0.250 \mathrm{~g}, 0.233 \mathrm{mmol}), 0.95$ eq. of dibrominated monomer and $5 \mathrm{~mol} \%$ of tetrakis(triphenylphosphine) palladium (0). The vial was sealed and $1 \mathrm{~mL}$ of $o$-xylene was added. The reaction mixture was degassed with argon during 30 minutes and submitted to the following temperature scheme in the microwave reactor: 5 minutes at $120^{\circ} \mathrm{C}, 5$ minutes at $140^{\circ} \mathrm{C}, 5$ minutes at $160^{\circ} \mathrm{C}$ and 40 minutes at $170^{\circ} \mathrm{C}$. The reaction mixture was cooled down to room temperature and 0.1 eq. of bromobenzene was added in one portion by syringe. The mixture was resubmitted to the microwave reactor, 1 minute at $100^{\circ} \mathrm{C}, 1$ minute at $120^{\circ} \mathrm{C}, 2$ 
Submitted to

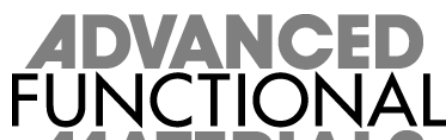

IAABLAS

1 minutes at $140^{\circ} \mathrm{C}$ and 5 minutes at $160^{\circ} \mathrm{C}$. Once the polymeric solution was cooled down, 0.1

2 eq. of trimethyl(phenyl)stannane was added by syringe. The reaction mixture was subjected

3 on last time to the previously mentioned temperature scheme to finalize the end-capping

4 reaction. After reaction, the crude polymer was precipitated in methanol and then further

5 purified by Soxhlet extractions with acetone, hexane and chloroform, each for 24 hours.

6 Remaining palladium residues were removed by treating a polymeric chloroform solution

7 with an aqueous sodium diethyldithiocarbamate solution for 2 hours at $50^{\circ} \mathrm{C}$ under vigorous

8 stirring. Afterwards the organic phase was separated from the aqueous phase and washed

9 several times with water. The polymeric solution was concentrated under reduced pressure and precipitated into cold methanol. The recovered polymer was dried under high vacuum for 11 at least 24 hours.

Condition B. A $5 \mathrm{~mL}$ microwave vial was charged with with bis(trimethylstannyl) monomer $1(0.250 \mathrm{~g}, \quad 0.233 \mathrm{mmol}), \quad 0.95 \mathrm{eq} . \quad$ of dibrominated monomer, $2 \mathrm{~mol} \%$ of 14 tris(dibenzylideneacetone)dipalladium (0) and $8 \mathrm{~mol} \%$ of tri( $o$-tolyl) phosphine. The vial was sealed and chlorobenzene $(1 \mathrm{~mL})$ was added. The obtained solution was degassed with argon during 30 minutes. The vial was subjected to the following reaction conditions in the microwave reactor: 2 minutes at $100^{\circ} \mathrm{C}, 2$ minutes at $120^{\circ} \mathrm{C}, 5$ minutes at $140^{\circ} \mathrm{C}, 5$ minutes at $160^{\circ} \mathrm{C}$ and 40 minutes at $170^{\circ} \mathrm{C}$. The polymer was end-capped by addition of 0.1 eq. of bromobenzene before the reaction mixture was resubmitted to the microwave reactor, 1 minute at $100^{\circ} \mathrm{C}, 1$ minute at $120^{\circ} \mathrm{C}, 2$ minutes at $140^{\circ} \mathrm{C}$ and 5 minutes at $160^{\circ} \mathrm{C}$. The polymeric solution was cooled down and 0.1 eq. of trimethyl(phenyl) stannane was added by syringe. The reaction vial was subjected to the previously mentioned temperature scheme to finalize the end-capping reaction. After reaction, the crude polymer was precipitated in methanol and then further purified by Soxhlet extractions with acetone, hexane and 25 chloroform during 24 hours each. Remaining palladium residues were removed by treating a 
Submitted to

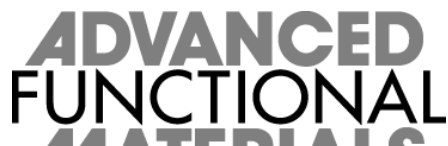

polymeric chloroform solution with an aqueous sodium diethyldithiocarbamate solution for 2

2 hours at $50^{\circ} \mathrm{C}$ under vigorous stirring. Afterwards the organic phase was separated from the aqueous phase and washed several times with water. The polymeric solution was concentrated under reduced pressure and precipitated into cold methanol. The polymer was filtered off and dried under high vacuum for at least 24 hours.

SiIDT-BT. Dark-blue solid (135 mg, $0.131 \mathrm{mmol}, 59 \%) . \mathrm{M}_{\mathrm{n}}=30.0 \mathrm{~kg} \mathrm{~mol}^{-1}, \mathrm{M}_{\mathrm{w}}=58.9 \mathrm{~kg}$ $\mathrm{mol}^{-1}, \mathrm{PDI}=1.96 .{ }^{1} \mathrm{H}$ NMR $\left(o-\mathrm{DCB}-\mathrm{d}_{4}, 400 \mathrm{MHz}, 313 \mathrm{~K}, \delta\right): 8.73(\mathrm{~s}, 2 \mathrm{H}), 8.30(\mathrm{~s}, 2 \mathrm{H}), 8.20-$ 7.75 (bm, 2H), 1.91-1.71 (bm, 8H, $\mathrm{SiCH}_{2}$ ), 1.63-1.50 (bm, 8H, $\mathrm{CH}_{2}$ ), 1.49-1.18 (bm, 40H, $\left.\mathrm{CH}_{2}\right), 1.04\left(\mathrm{t}, J=7 \mathrm{~Hz}, 12 \mathrm{H}, \mathrm{CH}_{3}\right)$.

SiIDT-DTBT. Dark-blue solid (151 mg, $0.13 \mathrm{mmol}, 63 \%) . \mathrm{M}_{\mathrm{n}}=22.3 \mathrm{~kg} \mathrm{~mol}^{-1}, \mathrm{M}_{\mathrm{w}}=56.6$ $\mathrm{kg} \mathrm{mol}^{-1}, \mathrm{PDI}=2.54 .{ }^{1} \mathrm{H}$ NMR $\left(o-\mathrm{DCB}-\mathrm{d}_{4}, 400 \mathrm{MHz}, 313 \mathrm{~K}, \delta\right): 8.31(\mathrm{~s}, 2 \mathrm{H}, \mathrm{Ar} \mathrm{H}), 8.19-8.07$ (m, 2H, Ar H), 8.01-7.83 (bm, 2H, Ar H), 7.80-7.71 (m, 2H, Ar H), 7.67-7.45 (bm, 2H, Ar H), 1.85-1.69 (bm, 8H, CH 2$), 1.61-1.52\left(\mathrm{bm}, 8 \mathrm{H}, \mathrm{CH}_{2}\right), 1.50-1.23\left(\mathrm{bm}, 40 \mathrm{H}, \mathrm{CH}_{2}\right), 1.07$ (t, $J=$ $\left.7 \mathrm{~Hz}, 12 \mathrm{H}, \mathrm{CH}_{3}\right)$.

SiIDT-2FBT. Dark-blue solid (102 mg, $0.11 \mathrm{mmol}, 51 \%) . \mathrm{M}_{\mathrm{n}}=21.0 \mathrm{~kg} \mathrm{~mol}^{-1}, \mathrm{M}_{\mathrm{w}}=35.3 \mathrm{~kg}$ $\mathrm{mol}^{-1}, \mathrm{PDI}=1.68 .{ }^{1} \mathrm{H}$ NMR $\left(o-\mathrm{DCB}-\mathrm{d}_{4}, 400 \mathrm{MHz}, 313 \mathrm{~K}, \delta\right): 8.91(\mathrm{~s}, 2 \mathrm{H}, \mathrm{Ar} \mathrm{H}), 8.36(\mathrm{~s}, 2 \mathrm{H}$, Ar H), 1.94-1.68 (bm, 8H, $\mathrm{CH}_{2}$ ), 1.63-1.50 (bm, 8H, $\mathrm{CH}_{2}$ ), 1.49-1.25 (bm, 40H, $\mathrm{CH}_{2}$ ), 1.05 (t, $\left.J=7 \mathrm{~Hz}, 12 \mathrm{H}, \mathrm{CH}_{3}\right)$.

SiIDT-2FDTBT. Dark-blue solid (142 mg, $0.12 \mathrm{mmol}, 55 \%) . \mathrm{M}_{\mathrm{n}}=26.4 \mathrm{~kg} \mathrm{~mol}^{-1}, \mathrm{M}_{\mathrm{w}}=71.0$ $\mathrm{kg} \mathrm{mol}^{-1}, \mathrm{PDI}=2.69 .{ }^{1} \mathrm{H} \mathrm{NMR}\left(o-\mathrm{DCB}-\mathrm{d}_{4}, 400 \mathrm{MHz}, 313 \mathrm{~K}, \delta\right): 8.52(\mathrm{~s}, 2 \mathrm{H}, \mathrm{Ar} \mathrm{H}), 8.24-7.97$ (m, 2H, Ar H), 7.88-7.44 (bm, 4H, Ar H), 1.86-1.71 (bm, 8H, $\left.\mathrm{CH}_{2}\right), 1.69-1.27$ (bm, 48H, $\left.\mathrm{CH}_{2}\right), 1.17-1,01\left(\mathrm{~m}, 12 \mathrm{H}, \mathrm{CH}_{3}\right)$.

Device Fabrication and Testing: Top-gate, bottom-contact organic field effect transistors (FETs) were fabricated on glass with pentafluorobenzenethiol (PFBT) treated Au electrodes, CYTOP (900 nm) dielectric and $\mathrm{Al}$ gate. Polymer films were spin cast from $o$ - 
Submitted to
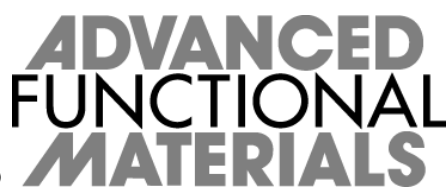

1 dichlorobenzene $(10 \mathrm{mg} / \mathrm{mL})$ solutions at a speed of $2000 \mathrm{rpm}$ and annealed at $180{ }^{\circ} \mathrm{C}$ for 10

2 minutes. The carrier mobility of the films was assessed by measuring transfer curves in

3 saturation $\left(\mathrm{V}_{\mathrm{DS}}=-60 \mathrm{~V}\right)$ using a Keithley 4200 semiconductor parameter analyzer. The

4 saturation mobility was determined by fitting a linear relationship of the square root of the

5 drain current to gate potential in the range of -40 to $-60 \mathrm{~V}$ and averaged over 3 devices.

All organic photovoltaic devices have a conventional device architecture,

ITO/PEDOT:PSS/Polymer: $\mathrm{PC}_{71} \mathrm{BM} / \mathrm{Ca} / \mathrm{Al}$. The precoated ITO glass substrates were cleaned with acetone and isopropyl alcohol under sonification, followed by drying and oxygen plasma treatment during 7 minutes. A $30 \mathrm{~nm}$ layer of PEDOT:PSS was spin-coated onto the plasmatreated ITO substrate and baked at $150^{\circ} \mathrm{C}$ for 20 minutes. An $80 \mathrm{~nm}$ active layer consisting of a 1:3 blend of polymer, respectively 1:3.5 for the SiIDT-BT polymer, and $\mathrm{PC}_{70} \mathrm{BM}$ dissolved in $o$-dichlorobenzene (ODCB) was spin-coated on the PEDOT:PSS layer and then Ca (30 $\mathrm{nm}) / \mathrm{Al}(100 \mathrm{~nm})$ cathode was finally deposited by thermal evaporation under high vacuum $\left(10^{-6}\right.$ mbar) through a shadow mask. The pixel size, defined by the spatial overlap of the ITO anode and $\mathrm{Ca} / \mathrm{Al}$ cathode, was $0.045 \mathrm{~cm}^{2}$. The device characteristics were obtained using a xenon lamp at AM1.5 solar illumination (Oriel Instruments). Short circuit currents under AM1.5G conditions were obtained from the spectral response and convolution with the solar spectrum, measured with a Keithley source meter. Spectral response was measured under operation conditions using bias light from a $532 \mathrm{~nm}$ solid state laser (Edmund Optics). Monochromatic light from a $100 \mathrm{~W}$ tungsten halogen lamp in combination with monochromator (Oriel, Cornerstone 130) was modulated with a mechanical chopper. The response was recorded as the voltage over a $50 \Omega$ resistance, using a lock-in amplifier (Stanford research Systems SR830). A calibrated Si cell was used as reference. All the device measurements were carried out behind a quartz window in a nitrogen filled container.

\section{Supporting Information}


Submitted to

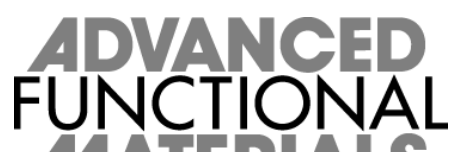

414 a

1 Supporting Information is available from the Wiley Online Library or from the author.

\section{Acknowledgements}

3 The authors would like to acknowledge Dr. Ester Buchaca Domingo for the DSC

4 measurements and the Imperial College High Performance Computing Service for providing

Received: ((will be filled in by the editorial staff))

Revised: ((will be filled in by the editorial staff)) Published online: ((will be filled in by the editorial staff))

[1] a) I. McCulloch, M. Heeney, M. L. Chabinyc, D. DeLongchamp, R. J. Kline, M. Cölle, W. Duffy, D. Fischer, D. Gundlach, B. Hamadani, R. Hamilton, L. Richter, A. Salleo, M. Shkunov, D. Sparrowe, S. Tierney, W. Zhang, Adv. Mater. 2009, 21, 1091; b) J. Sun, B. Zhang, H. E. Katz, Adv. Funct. Mater. 2011, 21, 29; c) Y. Liang, Z. Xu, J. Xia, S. Tsai, Y. Wu, G. Li, C. Ray, L. Yu, Adv. Mater. 2010, 22, E135; d) A. Facchetti, Chem. Mater. 2011, $23,733$.

[2] a) T. M. Clarke, A. M. Ballantyne, S. Tierney, M. Heeney, W. Duffy, I. McCulloch, J. Nelson, J. R. Durrant, J. Phys. Chem. C 2010, 114, 8068; b) C. J. Brabec, M. Heeney, I. McCulloch, J. Nelson, Chem. Soc. Rev. 2011, 40, 1185.

[3] a) G. Lu, H. Usta, C. Risko, L. Wang, A. Facchetti, M. A. Ratner, T. J. Marks, J. Am. Chem. Soc. 2008, 130, 7670; b) W. Zhang, J. Smith, S. E. Watkins, R. Gysel, M. McGehee, A. Salleo, J. Kirkpatrick, S. Ashraf, T. Anthopoulos, M. Heeney, I. McCulloch, J. Am. Chem. Soc. 2010, 132, 11437; c) Y.-C. Chen, C.-Y. Yu, Y.-L. Fan, L.-I. Hung, C.-P. Chen, C. Ting, 
Submitted to

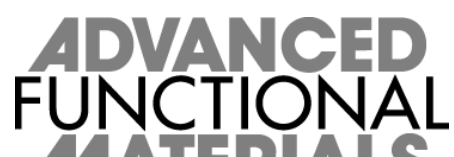

Chem. Comm. 2010, 46, 6503; d) Y. Zhang, J. Zou, H.-L. Yip, K.-S. Chen, D. F. Zeigler, Y.

2 Sun, A. K.-Y. Jen, Chem. Mater. 2011, 23, 2289.

3 [4] I. Osaka, R. D. McCullough, Acc. Chem. Res. 2008, 41, 1202.

4 [5] a) J. Wang, S. K. Hau, H. Yip, J. A. Davies, K. Chen, Y. Zhang, Y. Sun, A. K.-Y. Jen,

5 Chem. Mater. 2011, 23, 765; b) R. S. Ashraf, Z. Chen, D. Seok Leem, H. Bronstein, W.

Zhang, B. Schroeder, Y. Geerts, J. Smith, S. Watkins, T. W. Anthopoulos, H. Sirringhaus, J.

C. de Mello, M. Heeney, I. McCulloch, Chem. Mater. 2011, 23, 768.

8 [6] J. Ohshita, M. Nodono, H. Kai, T. Watanabe, A. Kunai, K. Komaguchi, M. Shiotani,

9 A. Adachi, K. Okita, Y. Harima, K. Yamashita, M. Ishikawa, Organometallics 1999, $18,1453$.

10 [7] a) S. C. Price, A. C. Stuart, L. Yang, H. Zhou, W. You, J. Am. Chem. Soc. 2011, 133,

11 4625; b) H. Zhou, L. Yang, A. C. Stuart, S. C. Price, S. Liu, W. You, Angew. Chem. Int. Ed. $12 \mathbf{2 0 1 1}, 50,2995$.

13 [8] H. Chen, J. Hou, S. Zhang, Y. Liang, G. Yang, Y. Yang, L. Yu, Y. Wu, G. Li, Nature 14 Photonics 2009, 3, 649.

15 [9] J. K. Park, J. Jo, J. Hwa Seo, J. Sun Moon, Y. Don Park, K. Lee, A. J. Heeger, G. C. 16 Bazan, Adv. Mater. 2011, 23, 2430.

17 [10] J. C. Slater, J. Chem. Phys. 1964, 41, 3199.

18 [11] a) N. Hergué, P. Leriche, P. Blanchard, M. Allain, N. Gallego-Planas, P. Frère, J. 19 Roncali, New J. Chem. 2008, 32, 932; b) D.J. Crouch, P. J. Skabara, J. E. Lohr, J. J. W. 20 McDouall, M. Heeney, I. McCulloch, D. Sparrowe, M. Shkunov, S. J. Coles, P. N. Horton, M. 21 B. Hursthouse, Chem. Mater. 2005, 17, 6567.

22 [12] C. Risko, M. D. McGehee, J-L. Brédas, Chem. Sci. 2011, 2, 1200.

23 [13] a) H. Bronstein, Z. Chen, R. S. Ashraf, W. Zhang, J. Du, J. R. Durrant, P. S. Tuladhar, 24 K. Song, S. E. Watkins, Y. Geerts, M. M. Wienk, R. A. J. Janssen, T. Anthopoulos, H. 25 Sirringhaus, M. Heeney, I. McCulloch, J. Am. Chem. Soc. 2011, 133, 3272; b) X. Zhang, L. J. 


\section{Submitted to

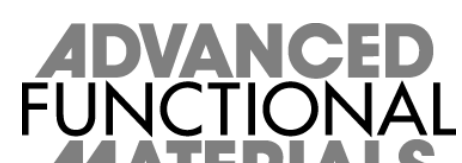

1 Richter, D. M. DeLongchamp, R. J. Kline, M. R. Hammond, I. McCulloch, M. Heeney, R. S.

2 Ashraf, J. N. Smith, T. D. Anthopoulos, B. Schroeder, Y. H. Geerts, D. A. Fischer, M. F.

3 Toney, J. Am. Chem. Soc. 2011, 133, 15073; c) H. Bronstein, D. S. Leem, R. Hamilton, P.

4 Woebkenberg, S. King, W. Zhang, R. S. Ashraf, M. Heeney, T. D. Anthopoulos, J. de Mello,

5 I. McCulloch, Macromolecules 2011, 44, 6649.

6 [14] H. Jung Son, W. Wang, T. Xu, Y. Liang, Y. Wu, G. Li, L. Yu, J. Am. Chem. Soc. 2011, 7133.

8 
1

3

4
5

9

10

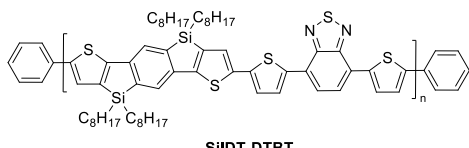

8

SilDT-DTBT

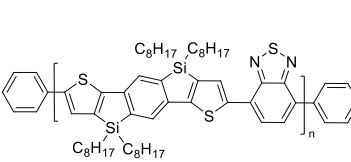

SIDT-BT

6

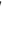
microwave heating.

11 Table 1. Molecular weights and thermal properties of the polymers.

\section{ADVNNCER
FUNCIONALL}

Figures and captions:
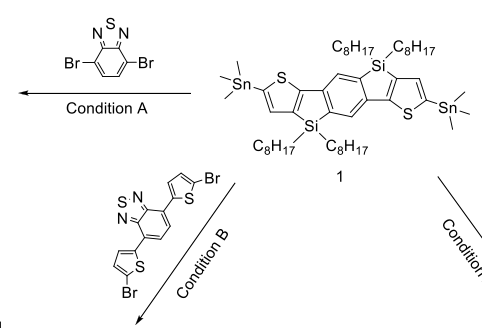
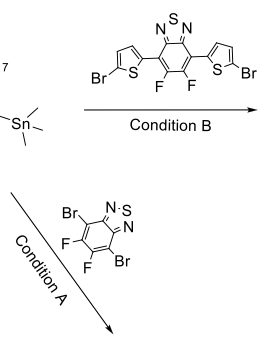

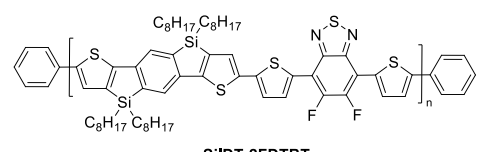

SilDT-2FDTBT

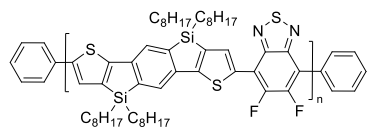

SilDT-2FBT

Scheme 1. Synthesis of the SiIDT based polymers; polymerization condition A: $\operatorname{Pd}\left(\mathrm{PPh}_{3}\right)_{4}, o$ xylene, microwave heating; polymerization condition $\mathrm{B}$ : $\mathrm{Pd}_{2}(\mathrm{dba})_{3}, \mathrm{P}(\mathrm{o}-\mathrm{tol})_{3}$, chlorobenzene,

\begin{tabular}{llllll}
\hline Polymer & $\mathrm{M}_{\mathrm{n}}[\mathrm{kg} / \mathrm{mol}][\mathrm{a}]$ & $\mathrm{M}_{\mathrm{w}}[\mathrm{kg} / \mathrm{mol}][\mathrm{a}]$ & $\mathrm{PDI}[\mathrm{a}]$ & $\mathrm{DP}_{\mathrm{n}}$ & $\mathrm{T}_{\mathrm{d}}\left[{ }^{[} \mathrm{C}\right][\mathrm{b}]$ \\
\hline SilDT-BT & 30.0 & 58.9 & 1.96 & 34 & 443 \\
SilDT-DTBT & 22.3 & 56.6 & 2.54 & 21 & 444 \\
SilDT-2FBT & 21.0 & 35.3 & 1.68 & 23 & 428 \\
SilDT-2FDTBT & 26.4 & 71.0 & 2.69 & 24 & 431 \\
\hline
\end{tabular}

12 [a] Determined by GPC using polystyrene standards and chlorobenzene as eluent. [b] 5\%

13 weight loss temperatures measured by TGA under nitrogen atmosphere. 


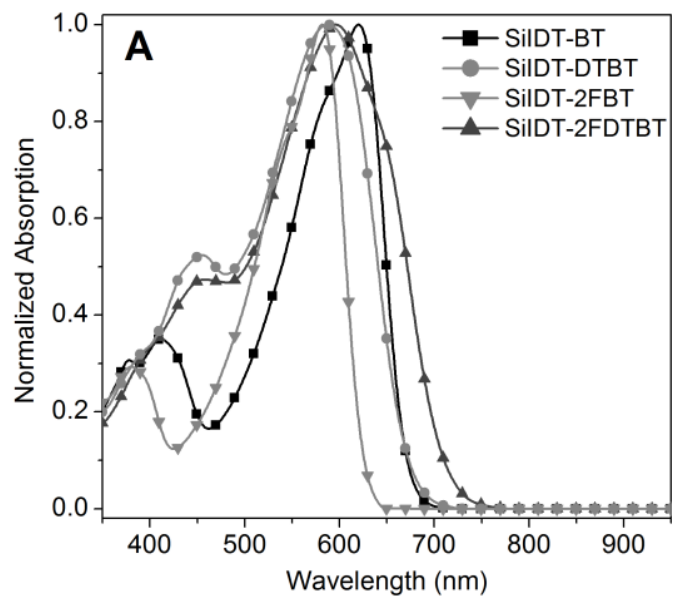

Submitted to 14 A

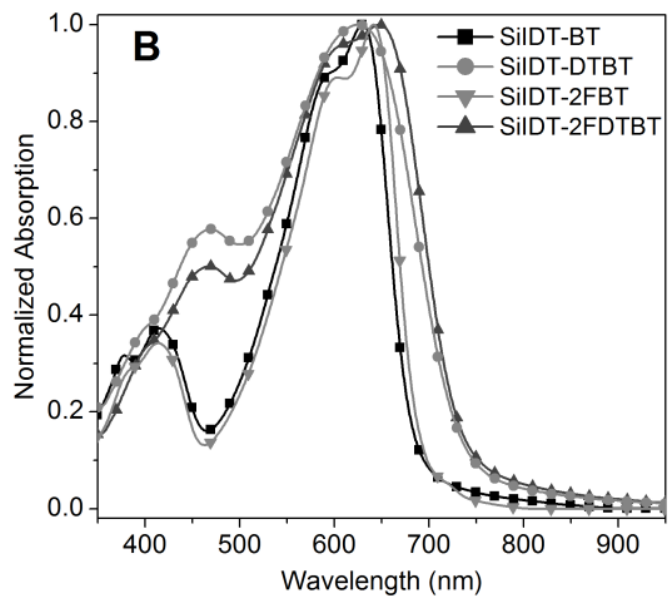

2 Figure 1. Normalized UV-vis. absorption spectra of SiIDT based polymers in dilute

3 chlorobenzene solution (A) and thin-film (B), spin-cast from chlorobenzene.

6 Table 2. Optical properties and experimental and calculated energy levels of SiIDT based

7 polymers.

\begin{tabular}{|c|c|c|c|c|c|c|c|c|}
\hline & & & PESA & $\begin{array}{l}\text { Cyclic } \\
\text { voltammetry }\end{array}$ & DFT & & & \\
\hline Polymer & $\begin{array}{l}\lambda_{\max } \text { soln. } \\
{[\mathrm{nm}][\mathrm{a}]}\end{array}$ & $\begin{array}{l}\lambda_{\max } \text { film } \\
{[\mathrm{nm}][\mathrm{b}]}\end{array}$ & $\begin{array}{l}\mathrm{HOMO} / \mathrm{LUMO} \\
{[\mathrm{eV}][\mathrm{c}]}\end{array}$ & $\begin{array}{l}\mathrm{HOMO} / \mathrm{LUMO} \\
{[\mathrm{eV}]}\end{array}$ & $\begin{array}{l}\mathrm{HOMO} / \mathrm{LUMO} \\
{[\mathrm{eV}]}\end{array}$ & $\begin{array}{l}E_{g}{ }^{o p t} \\
{[e V]}\end{array}$ & $\begin{array}{l}\mathrm{E}_{\mathrm{g}}^{\mathrm{EC}} \\
{[\mathrm{eV}]}\end{array}$ & $\begin{array}{l}\mathrm{E}_{g}^{\text {calc }} \\
{[\mathrm{eV}]}\end{array}$ \\
\hline SilDT-BT & 412,620 & 414,634 & $-5.4 /-3.6$ & $-5.3 /-3.1$ & $-4.7 /-3.0$ & 1.8 & 2.2 & 1.7 \\
\hline SilDT-DTBT & 454,588 & 468,625 & $-5.0 /-3.3$ & $-5.2 /-3.4$ & $-4.6 /-3.0$ & 1.7 & 1.8 & 1.6 \\
\hline SilDT-2FBT & 381,582 & 413,642 & $-5.4 /-3.6$ & $-5.3 /-3.1$ & $-4.8 /-3.1$ & 1.8 & 2.2 & 1.7 \\
\hline SiIDT-2FDTBT & 457,597 & 468,648 & $-5.1 /-3.4$ & $-5.2 /-3.2$ & $-4.7 /-3.1$ & 1.7 & 2.0 & 1.6 \\
\hline
\end{tabular}

8 [a] Measured in dilute chlorobenzene solution. [b] Spin-coated from $5 \mathrm{mg} / \mathrm{mL}$ chlorobenzene

9 solution. [c] The LUMO energy is estimated by adding the absorption onset to the HOMO. 
A

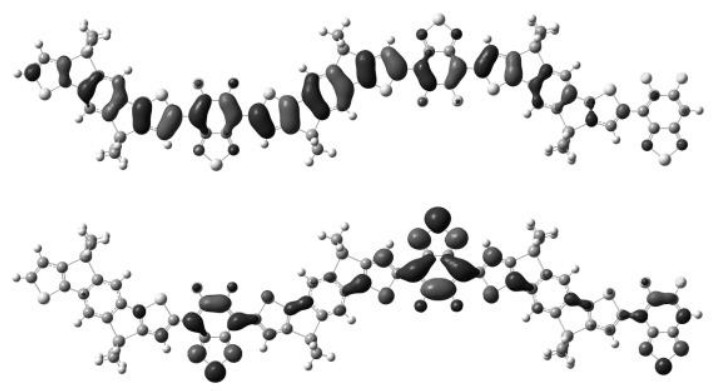

$\mathbf{B}$
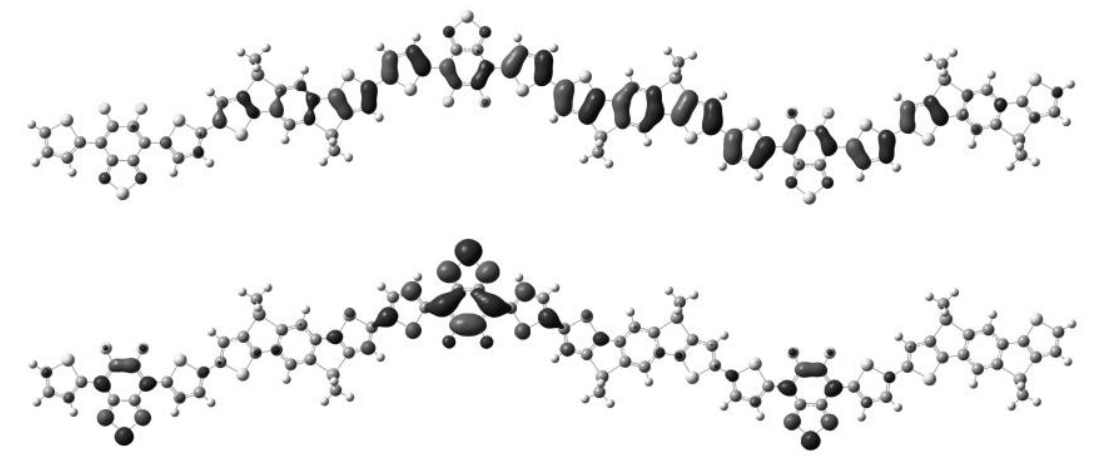

Figure 2. Energy-minimized structure (B3LYP/6-31G*) of a methyl-substituted SiIDT-2FBT
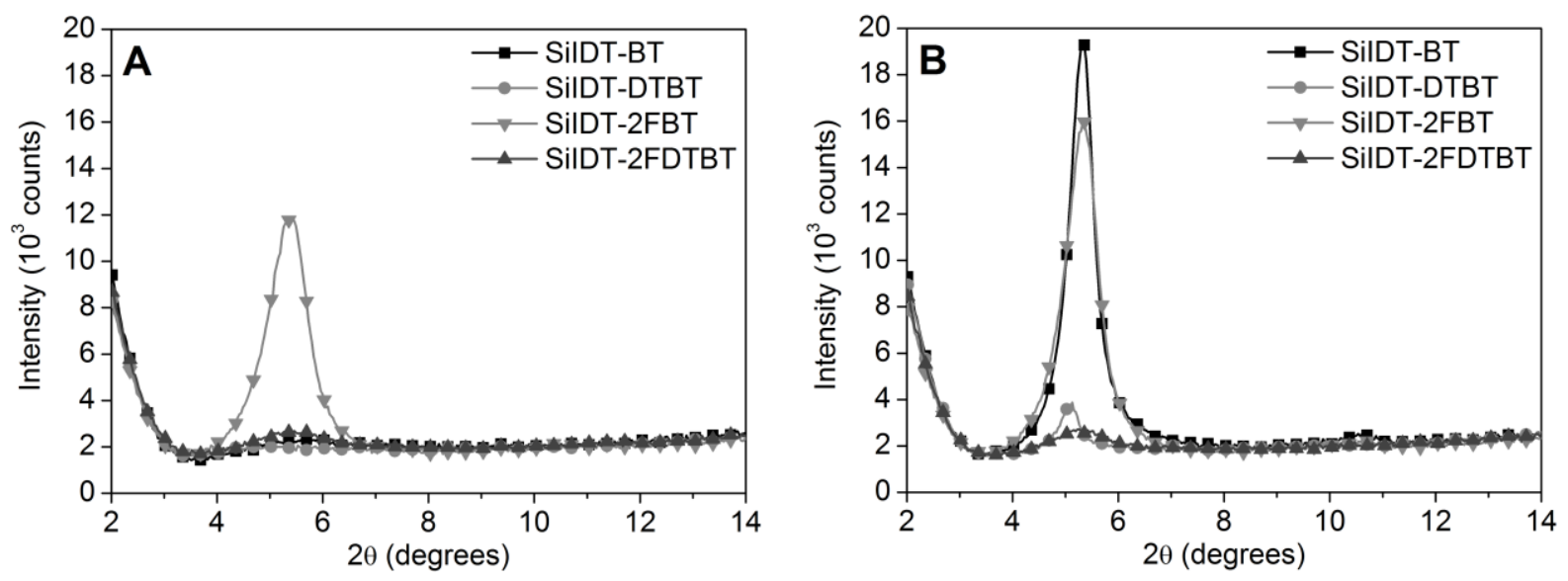

Figure 3. X-ray diffraction (XRD) patterns of drop-cast films of pristine SiIDT polymers on glass substrates (A) and after annealing at $180^{\circ} \mathrm{C}$ for 10 minutes under nitrogen atmosphere (B). 


\section{Submitted to

2 Table 3. OFET Device Characteristics of SiIDT polymers.

\begin{tabular}{llll}
\hline Polymer & $\mu_{\text {sat }}\left[\mathrm{cm}^{2} / \mathrm{Vs}\right][\mathrm{a}]$ & $\mu_{\text {lin }}\left[\mathrm{cm}^{2} / \mathrm{Vs}\right][\mathrm{b}]$ & $\mathrm{I}_{\text {on }} / I_{\text {off }}[\mathrm{a}]$ \\
\hline SilDT-BT & 0.014 & 0.011 & $\sim 10^{4}$ \\
SilDT-DTBT & 0.28 & 0.25 & $\sim 10^{3}$ \\
SilDT-2FBT & 0.004 & 0.002 & $\sim 10^{3}$ \\
SilDT-2FDTBT & 0.19 & 0.10 & $\sim 10^{4}$ \\
\hline
\end{tabular}

3 [a] $\mu_{\text {sat }}$ refer to the highest effective hole mobilities measured in the saturation regime. $[b] \mu$ lin

4 refer to the highest effective hole mobilities measured in the linear regime. The on-to-off $5 \operatorname{ratios}\left(\mathrm{I}_{\mathrm{on}} / \mathrm{I}_{\mathrm{off}}\right)$ were extracted from the linear regime.

6
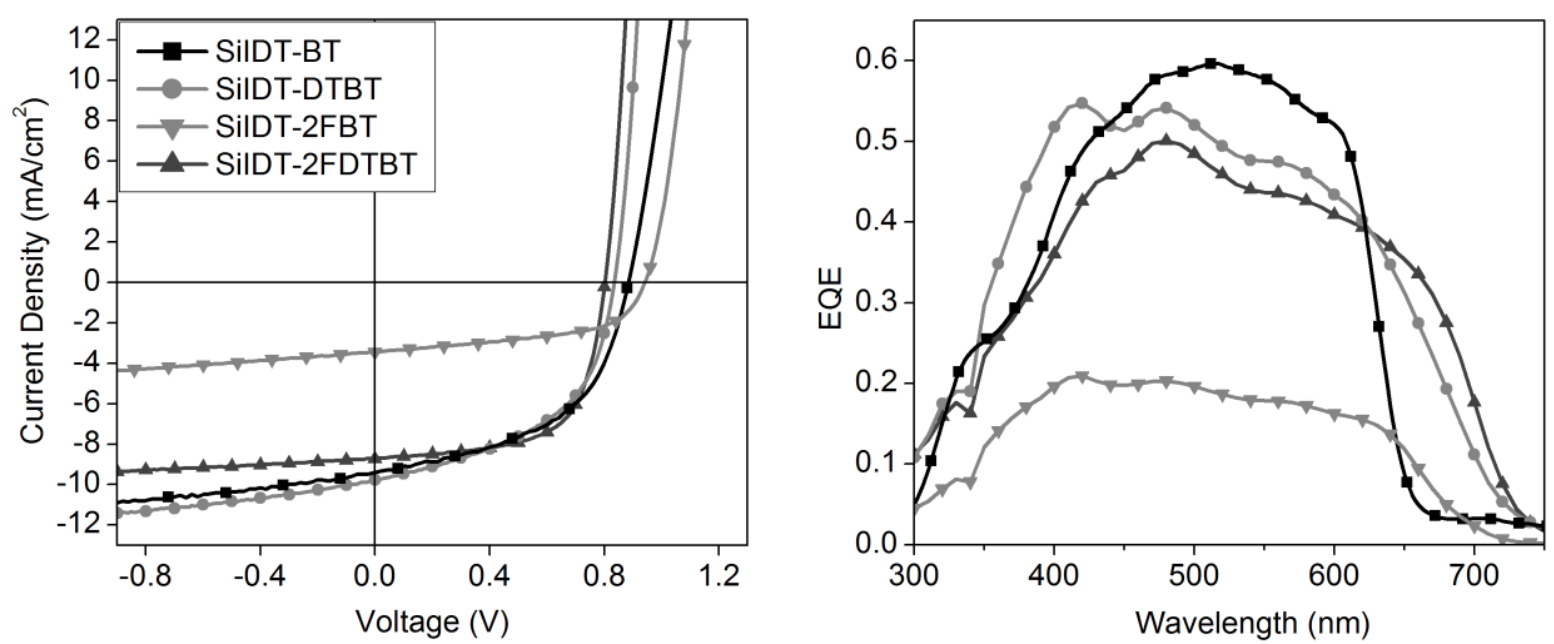

8 Figure 4. (left) $\mathrm{J}-\mathrm{V}$ characteristics of SiIDT polymer:PC ${ }_{71} \mathrm{BM}$ solar cell under AM1.5 solar

9 illumination and (right) external quantum efficiencies of the cells. 


\section{Submitted to \\ FUNCTIONAL}

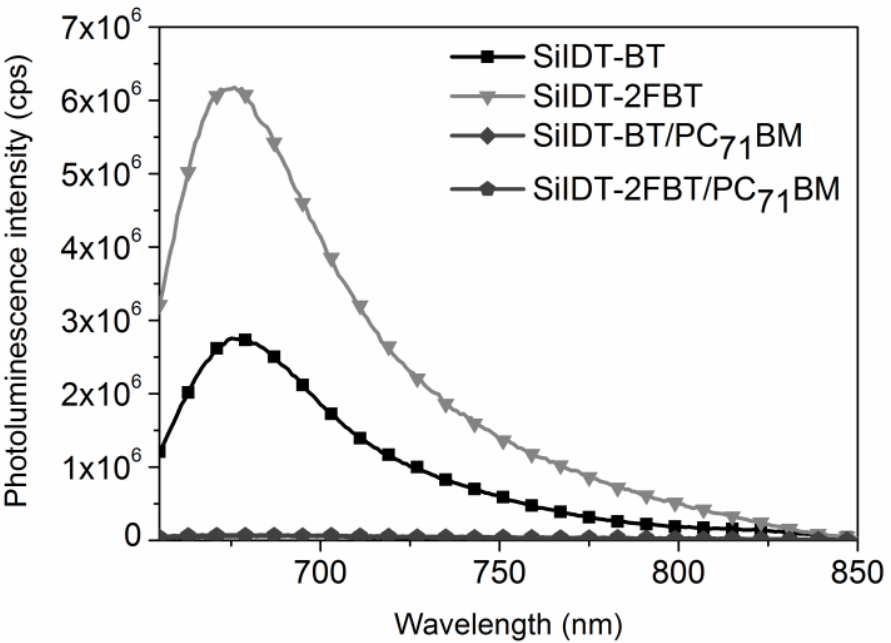

Figure 5. Photoluminescence spectra of thin films of SiIDT-BT, SiIDT-2FBT, SiIDT-
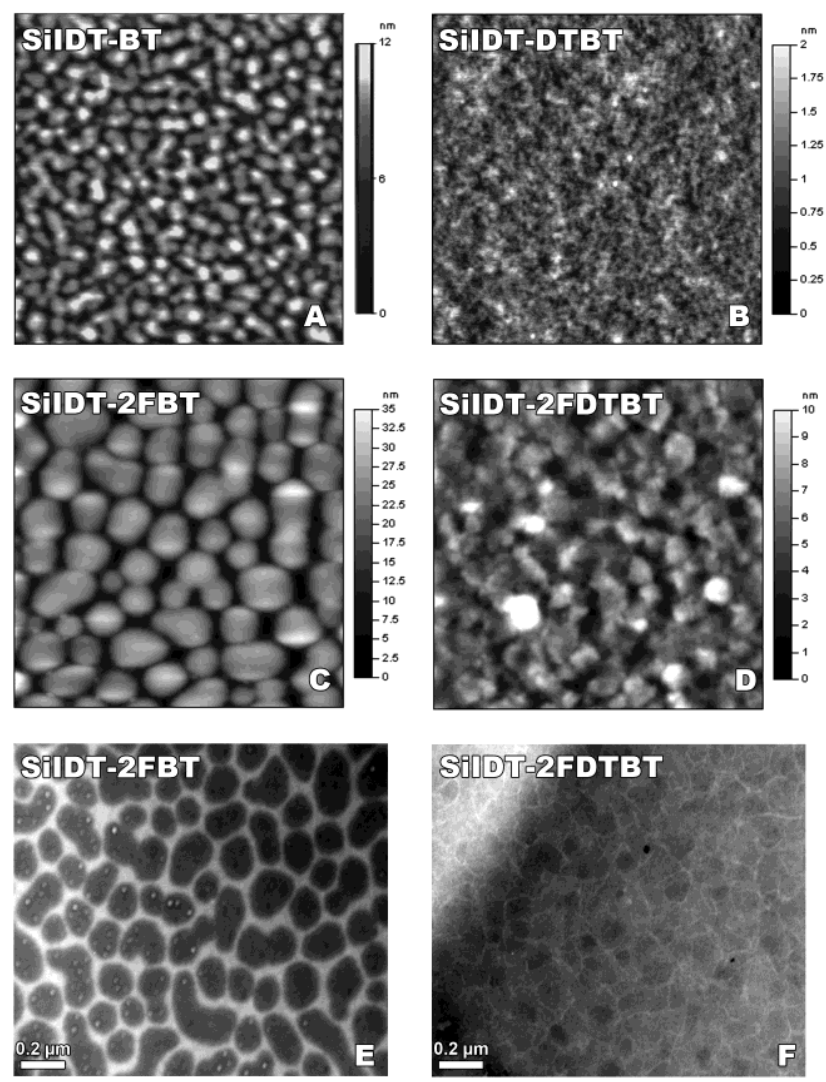

6 Figure 6. A to D: AFM topography images $(2.0 \mu \mathrm{m} \times 2.0 \mu \mathrm{m})$ of $1: 3 \mathrm{w} / \mathrm{w}$ polymer/PC $71 \mathrm{BM}$

7 blends (except for SiIDT-BT which is a 1:3.5 polymer:PC ${ }_{71} \mathrm{BM}$ blend). E and F: TEM images of SiIDT-2FBT and SiIDT-2FDTBT. 


\section{Submitted to FUNCTIONAL \\ MATERIALS}

1

2 Table 4. OPV Device Characteristics of SiIDT polymers

\begin{tabular}{lllll}
\hline \multicolumn{1}{c}{ Polymer } & $\mathrm{J}_{\mathrm{sc}}\left[\mathrm{mA} / \mathrm{cm}^{2}\right]$ & $\mathrm{V}_{\mathrm{OC}}[\mathrm{V}]$ & $\mathrm{FF}$ & $\mathrm{PCE}[\%]$ \\
\hline SilDT-BT & 9.93 & 0.88 & 0.52 & 4.5 \\
SilDT-DTBT & 8.75 & 0.83 & 0.50 & 3.6 \\
SilDT-2FBT & 3.44 & 0.94 & 0.54 & 1.7 \\
SilDT-2FDTBT & 8.36 & 0.80 & 0.64 & 4.3 \\
\hline
\end{tabular}

3

4 


\section{The table of contents entry.}

Fluorine is introduced into silaindacenodithiophene based semi-conducting polymers with the aim to improve the photovoltaic as well as the charge carrier properties. The influence of the thienyl spacers and fluorine atoms on molecular packing and active layer morphology of the new polymers is investigated with regard to device performances.

Keywords: silaindacenodithiophene, hole mobility, solar cell, fluorine, conjugated polymers

Bob C. Schroeder, Zhenggang Huang, Raja Shahid Ashraf, * Jeremy Smith, Pasquale D’ Angelo, Scott E. Watkins, Thomas D. Anthopoulos, James R. Durrant and Iain McCulloch

Silaindacenodithiophene based low band gap polymers - the effect of fluorine substitution on device performances and film morphologies.
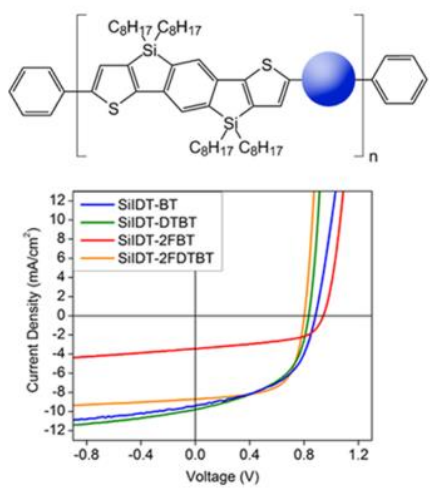